Published in final edited form as:

Pharmacol Res. 2011 August ; 64(2): 136-145. doi:10.1016/j.phrs.2011.03.009.

\title{
Tea and Cardiovascular Disease
}

\author{
Apranta Deka, MD and Joseph A. Vita, MD \\ Evans Department of Medicine and the Whitaker Cardiovascular Institute, Boston University \\ School of Medicine, Boston, MA
}

\begin{abstract}
There is increasing evidence for a protective effect of tea consumption against cardiovascular disease. This review summarizes the available epidemiological data providing evidence for and against such an effect. We also review observational and intervention studies that investigated an effect of tea and tea extracts on cardiovascular risk factors, including blood pressure, serum lipids, diabetes mellitus, and obesity. Finally, we review potential mechanisms of benefit, including antiinflammatory, anti-oxidant, and anti-proliferative effects, as well as favorable effects on endothelial function. Overall, the observational data suggest a benefit, but results are mixed and likely confounded by lifestyle and background dietary factors. The weight of evidence indicates favorable effects on risk factors and a number of plausible mechanisms have been elucidated in experimental and translational human studies. Despite the growing body evidence, it remains uncertain whether tea consumption should be recommended to the general population or to patients as a strategy to reduce cardiovascular risk.
\end{abstract}

\section{Keywords}

Tea; polyphenols; catechins; flavonoids; cardiovascular disease; endothelium

\section{Introduction}

Tea leaves are obtained from the Camillia Sinensis plant. Based on how the leaves are processed, three main types of tea can be produced: non-fermented green tea, partlyfermented oolong tea and fermented black tea. Records from as far back as the $10^{\text {th }}$ century $\mathrm{BC}$ indicate use of tea by man, largely because of its medicinal value. This review will focus on possible beneficial effects against cardiovascular disease

Tea leaves contain a large amount of polyphenols (about $30 \%$ of the dry substance), mainly flavonoids. The major class of flavonoids in tea are flavanols, which include catechin, epicatechin (EC), epigallocatechin (EGC), epicatechin gallate (ECG), and epigallocatechin gallate (EGCG) [1]. Total polyphenol content is similar in different types of tea, but the individual components vary, based in part on the degree of polyphenol oxidation during the manufacturing process. Catechins constitute about $80-90 \%$ and flavanols about $10 \%$ of the

\footnotetext{
(C) 2011 Elsevier Ltd. All rights reserved.

Address for Correspondence: Joseph A. Vita, MD, Professor of Medicine, Boston University School of Medicine, 88 East Newton Street, C-818, Boston, MA 02118, 1-617-638-8742, 1-617-638-8712 (FAX), jvita@bu.edu.

Publisher's Disclaimer: This is a PDF file of an unedited manuscript that has been accepted for publication. As a service to our customers we are providing this early version of the manuscript. The manuscript will undergo copyediting, typesetting, and review of the resulting proof before it is published in its final citable form. Please note that during the production process errors may be discovered which could affect the content, and all legal disclaimers that apply to the journal pertain.
} 
total flavonoids in green tea. On the other hand, theaflavins account for $50-60 \%$ and catechins only $20-30 \%$ of total flavonoids in black tea [2].

Recently, there has been considerable interest in the possibility that consumption of tea reduces risk for cardiovascular disease. Some observational studies suggest a benefit of tea, while other studies have failed to show such an association. Mechanistic studies have shown that tea and tea polyphenols have favorable effects on systemic risk factors and direct effects on the vasculature and platelets that might account for reduced cardiovascular risk. In the following sections, we will summarize the supportive and non-supportive observational studies that investigated a relationship between tea consumption and cardiovascular risk. We will then consider experimental, mechanistic and translational studies that elucidate potential mechanisms of benefit. Finally, we will attempt to put these data into clinical context given the considerable interest in dietary and lifestyle approaches to reduce cardiovascular disease.

\section{Epidemiologic studies with tea and cardiovascular disease events}

A large number of cross-sectional and prospective outcome studies investigated the relation between tea consumption and cardiovascular disease. In addition several meta-analyses have been performed that pool these data. Overall, the evidence suggests a benefit, for both green and black tea, but the results may be confounded by lifestyle and other dietary factors.

Nearly all of the published studies examining the relation between green tea consumption and cardiovascular risk suggest a reduction in risk. In an early study from Japan, Sato and colleagues followed a cohort of 5,910 women for four years and found that the incidence of stroke and cerebral hemorrhage was two times higher in those with daily green tea consumption less than five cups when compared to those with more than five cups [3]. More recent studies also showed a beneficial effect of green tea consumption in Japan. Nakachi and colleague studied a cohort of 8,552 participants and observed a $28 \%$ reduction in death from cardiovascular disease for men and women consuming over 10 cups a day compared to those consuming less than 3 cups per day [4]. Similarly, the Ohsaki National Health Insurance Cohort Study, which followed 40,530 Japanese adults for 11 years, demonstrated a dose relationship between increasing green tea consumption and reduced total and cardiovascular mortality that was strongest in women with a relative risk of $0.69(95 \% \mathrm{CI}$, 0.53-0.90) for women who consumed more than five cups per day [5]. Stroke mortality was particularly reduced in tea drinkers. A case-control study from China also suggested a favorable effect of green and oolong tea consumption against ischemic stroke [6].

Recently, a very large prospective study involving 76,979 Japanese adults examined the relationship between cardiovascular mortality and consumption of several different types of tea. The investigators reported a strong inverse relationship between cardiovascular mortality and consumption of more then six cups of green tea per day [7]. Interestingly, consumption of more than one cup of oolong tea per day was also associated with reduced risk in Japan [7]. Overall, these studies conducted in Japan and China suggested that consumption of relatively large amounts of green tea (5 to 10 cups per day) is associated with reduced cardiovascular events.

Studies performed in Europe and the U.S. suggested a benefit from consumption of black tea. For example, Sesso and colleagues completed a case-control study and observed that individuals with history of myocardial infarction were less likely to be consuming more than a cup of black tea per day compared to age, sex, and community-matched controls (odds ratio of 0.56) [8]. In the Determinants of Myocardial Infarction Onset Study, individuals consuming more than an average of two cups of black tea per day had lower total and cardiovascular mortality during 3.8-year follow-up compared to individuals consuming less tea [9]. The same study demonstrated lower prevalence of ventricular arrhythmia during 
hospitalization for myocardial infarction among tea drinkers, possibly suggesting less severe infarction and providing a potential explanation for the reduction in cardiovascular mortality observed during subsequent follow-up [10].

A large cohort of 37,514 participants in Netherlands was prospectively followed for 13 years with end points of cardiovascular disease morbidity and mortality [11]. In that study, consumption of tea (mainly black tea) 3 to 6 cups daily was associated with a reduced risk of cardiovascular disease mortality. There was no association, however, between tea consumption and all cause mortality. In that study, tea drinking was found to also be associated with a higher educational level, higher physical activity, healthier diet, and lower prevalence of smoking, hypercholesterolemia and diabetes. Although the investigators adjusted for these factors, residual confounding by health behavior could have affected the results. A study from a Norwegian cohort (Oppland County) of 9,856 men and 10,233 women showed a strong trend for a benefit of tea [12]. In that study, there were significant correlations between tea consumption and blood pressure and cholesterol levels, which were lower among individuals consuming one or more cups of tea per day.

Several epidemiological studies failed to show an association between tea consumption and cardiovascular disease. For example, in the Scottish Heart Health Study involving 10,359 men and women there was no association between tea consumption and prevalent coronary heart disease [13]. In a cohort of 1,900 Welsh men, the group with the highest consumption of tea (more than eight cups per day) actually had higher ischemic heart disease mortality compared to the group consuming less than two cups per day [14]. The authors pointed out that tea is often consumed with milk in the United Kingdom and speculated that milk might have affected absorption or increased fat intake and influenced a benefit of tea.

Other factors might explain the lack of benefit in these studies. For example, it has been noted that tea consumption is more common among individuals of low socioeconomic status in the U.K., and the association between lower social status and higher cardiovascular disease risk might obscure a beneficial effect of tea [15]. Another consideration is the baseline flavonoid intake. If the entire U.K. population has a relatively high level of tea intake, then even individuals in the lower range of consumption could be receiving the maximal benefits of tea. Conversely, a study in cohort with relatively low overall tea intake might fail to show a benefit even in the subgroup of individuals in the highest quartile or quintile of tea intake. In this regard, the relationship between tea consumption and cardiovascular events was only a non-significant trend $(\mathrm{P}=0.07)$ in the Women's Health Study, where only a small proportion of the women in the U.S. consumed more than four cups of tea per day [16]. Sesso and colleagues also observed no significant association between tea consumption and cardiovascular disease in a cohort of 17,228 college alumni (College Alumni Health Study) where the median intake of tea was relatively low (1 cup per day) [17]. This cohort also was relatively healthy and had higher socioeconomic status than some of the other studies, which also may have made it difficult to show a benefit of tea consumption. Such factors might also account for the lack of benefit of tea consumption in a cohort of 34,789 male health professionals [18].

Overall, the bulk of evidence does suggest that higher consumption of both green and black tea is associated with reduction of cardiovascular risk, despite the negative results of some studies. A number of meta-analyses have been performed to more formally address this question. For example, Peters and colleagues examined the relation of tea consumption to stroke, myocardial infarction, and all coronary heart disease in an analysis of 10 cohort studies and seven case-control studies [19]. The incidence of myocardial infarction was estimated to be $11 \%$ lower for an increase in tea consumption of 3 cups per day ( 1 cup= 237 $\mathrm{ml})$. Those investigators, however, acknowledged that their results need to be interpreted 
with caution because there was evidence of bias toward preferential publication of smaller positive studies [19]. Also, there was heterogeneity that could be explained by the geographic region where the studies were conducted. The same group pooled data from nine studies involving 194,965 individuals and concluded that consumption of three or more cups of green or black tea per day was associated reduced incidence of ischemic stroke [20].

In regard to the specific components of tea that are responsible for benefit, several epidemiological studies and meta-analyses have examined consumption of flavonoidcontaining foods more generally. In addition to tea, such foods include grapes and red wine, chocolate, apples, onions, and other fruits and vegetables. In the Zutphen Elderly Study, which examined a cohort of 805 Dutch men with five-year follow-up, dietary flavonoids were inversely associated with coronary heart disease mortality with relative risk of 0.42 for individuals in the highest versus lowest tertile of flavonoid intake [21]. A similar relationship was observed after 10-year follow-up that remained highly significant after adjustment for cardiovascular risk factors [22]. Flavonoid intake also was inversely related to stroke in the same cohort [23]. In the Seven Countries Study with 25 years of follow-up, there was an inverse correlation between flavonoid intake and incidence of coronary heart disease [24]. In a Finnish cohort of 25,372 male smokers, flavonol and flavone intake was inversely associated with myocardial infarction and there also was a trend for reduced coronary heart disease death [25].

In contrast, there was no significant correlation between flavonoid intake and cardiovascular disease events in a cohort of U.S. women participating in the Women's Health Study [16], but as previously noted, overall flavonoid intake in this cohort was relatively low. Overall, available evidence, including several meta-analyses suggests a benefit of flavonoid consumption against cardiovascular disease $[26,27]$

\section{Tea and risk factors for cardiovascular disease}

Given the apparent association between tea consumption and cardiovascular disease events, it is worthwhile to consider the potential mechanisms of benefit. One important potential mechanism is direct effect of tea on cardiovascular disease risk factors. A large number of epidemiological and intervention studies have examined this issue. Despite this large body of work, it remains unclear whether tea consumption has favorable effects on blood pressure, serum lipids, diabetes mellitus, or obesity in human subjects. If present, the beneficial effects of tea on risk factors are likely to be modest.

\subsection{Hypertension}

Epidemiological and intervention studies provide evidence that consumption of tea and other polyphenol-containing foods lower blood pressure. In a large epidemiological study involving over 20,000 Norwegian participants, systolic blood pressure was 2.1 and 3.5 $\mathrm{mmHg}$ lower in men and women, respectively, who consumed five or more cups of tea per day [12]. In a study of 218 elderly women, tea consumption and urine 4-O-methylgallic acid (a measure of polyphenol consumption) correlated inversely with systolic and diastolic blood pressure, with a $2.2 \mathrm{mmHg}$ lower systolic blood pressure for each cup of tea consumed [28]. While these absolute changes in blood pressure may seem small, changes of this magnitude on a population basis would result in the prevention of many cardiovascular events and strokes [29]. Yang and colleagues examined incident hypertension in a cohort of 1,507 men and women in Taiwan and observed a reduction in the risk of developing new hypertension in individuals consuming more than $120 \mathrm{ml}$ of green or oolong tea per day after adjusting for other risk factors, lifestyle, sodium intake, and coffee consumption [30]. On the other hand several very large studies have shown no relation between tea consumption and blood pressure [31-33]. 
Intervention studies provide additional information about the effects of tea consumption on blood pressure. This question is complicated because, in addition to flavonoids, tea contains caffeine, which causes a short-term increase in blood pressure. Hodgson observed an increase in blood pressure 30 min after ingestion of green or black tea in normotensive men that was no longer evident at 60 minutes after [34]. Interestingly, this increase in blood pressure was actually greater than the effect of an equivalent dose of caffeine alone suggesting that tea or tea polyphenols might cause acute increases blood pressure.

Consumption of either form of tea for seven days had no effect on 24-hour ambulatory blood pressure in the same population [34]. The same group of investigators observed that the acute hypertensive effect of tea consumption was blunted when tea was consumed with food [35].

Nagao and colleagues completed a study of green tea extract (583 $\mathrm{mg}$ of catechin) in Japanese men and women with abdominal obesity [36]. In the subgroup of participants with baseline systolic blood pressure of $130 \mathrm{mmHg}$ or higher, tea extract significantly reduced blood pressure compared to placebo [36]. Brown and colleagues examined the effects of EGCG on blood pressure and other metabolic risk factors in overweight or obese men and observed a $2.7 \mathrm{mmHg}$ reduction in diastolic blood pressure [37]. More recently, Nantz and colleagues completed a double-blind trial in 111 healthy volunteers comparing the effects of a standardized capsule containing $200 \mathrm{mg}$ of decaffeinated catechin green tea extract to placebo [38]. They observed a $5 \mathrm{mmHg}$ decrease in systolic blood pressure that was significantly different from the effect of placebo.

The apparently favorable effects of tea and tea components on blood pressure in intervention studies contrast with the results of a large number of other clinical studies examining the effects of tea on a variety of physiological endpoints. Taubert and colleagues recently completed a meta-analysis pooling five parallel group and cross-over studies that reported on the effects of tea on blood pressure in a total of 343 participants with a median duration of four weeks [39]. The meta-analysis revealed no significant effect of tea consumption on blood pressure. Interestingly, they did observe a favorable effect of chocolate consumption on blood pressure using the same approach.

Overall, the available studies do not provide a definitive answer to the question of whether tea consumption lowers blood pressure. Many of the studies examined normotensive populations and populations already well controlled on anti-hypertensive therapy, where it is difficult to demonstrate a blood pressure lowering effect with any intervention. Furthermore, few of the studies used 24-ambulatory blood pressure monitoring or treated subjects for an extended period of time. Any benefit of tea flavonoids must overcome the short-term blood pressure raising effects of caffeine. Thus, despite the large number of prior epidemiological and interventional studies, further definitive studies are needed to determine the acute and chronic effects of tea consumption on blood pressure in patients with hypertension and whether blood pressure effects could explain the observed associations between tea consumption and reduced cardiovascular risk.

\subsection{Dyslipidemia}

Improvement in serum lipid profile is another possible mechanism that would account for a beneficial effect of tea on cardiovascular disease, and several observational studies suggest that tea might have such an effect. Kono and colleagues reported that total serum cholesterol was $8 \mathrm{mg} / \mathrm{dl}$ lower in 1,306 Japanese men consuming nine or more cups of green tea per day [40]. Stensvold reported a comparable reduction in total cholesterol in Norwegian men and women consuming more than five cups of black tea per day [12]. On the other hand, several observational studies have shown no relationship between green or black tea consumption and total or LDL cholesterol levels [41,42]. 
The question of a lipid-lowering effect of tea has also been examined in randomized intervention studies that allow for control of potential confounding variables. Davies and colleagues completed a placebo controlled, double blind crossover study of five cups of black tea and placebo beverage in 15 mildly hypercholesterolemic adults and observed a reductions of $6.5 \%$ and $11.1 \%$ in total and LDL cholesterol, respectively [43]. In a much larger $(n=240)$ and well-designed randomized crossover study, Maron and colleagues observed comparable reductions in LDL cholesterol with consumption of flavin-enriched green tea for 12 weeks [44]. Several other intervention studies have shown cholesterol lowering effects of green and black tea as well as tea extracts [38,45-48] Other studies have failed to show such an effect [37,49-51]. Interestingly, there is evidence that tea consumption may have a favorable effect on post-prandial lipids, which are particularly atherogenic [45] and a favorable effect on HDL cholesterol in patients with diabetes mellitus [52].

Overall, the published studies examined many different patient populations with varying degree of baseline dyslipidemia and background therapy. The available studies also examined many different preparations and extracts of tea. This heterogeneity in study design likely explains the divergent results. In an extensive meta-analysis involving 133 interventions studies examining the effects of various flavonoid-containing foods, Hooper and colleagues concluded that green tea consumption has significant albeit modest LDL lowering effect [53].

1.3.3 Diabetes and obesity-Type 2 diabetes mellitus is a major cardiovascular disease risk factor and is increasing in prevalence, in large part due to the ongoing obesity epidemic [54]. Insulin resistance is the primary pathophysiological mechanism in type 2 diabetes mellitus, and there is experimental evidence that polyphenols found in tea can improve insulin sensitivity. Observational and intervention studies suggest that this mechanism may be operative in humans. In a study of 17,413 Japanese adults, Iso and colleagues reported that the incidence of new diabetes was inversely associated with consumption of more than six cups of green tea per day, while there was no association with black or oolong tea [55]. Interestingly, there also was an inverse association between diabetes mellitus and coffee consumption in that study. Greenberg and colleagues observed that consumption of two cups of "regular tea" (presumably black tea) per day was associated with a reduction in the incidence of diabetes during an 8.4 year follow-up period in participants of the National Health and Nutrition Examination Survey (NHANES) who were age 60 or younger [56]. On further subgroup analysis, this relationship applied to the individuals who had lost weight during the follow-up period. The Whitehall II study also showed decreased incidence of diabetes mellitus in 5,823 participants followed for 11.7 years that was not significant after adjustment for concomitant risk factors [57]. Finally, in the Women's Health Study, Song and colleagues observed a borderline significant relationship between tea consumption $(\geq 4$ cups day) and the incidence of new diabetes mellitus over an 8 year follow-up period with a relative risk of $0.72(95 \%$ CI $0.52-1.01)$ [58].

In contrast, several very large studies showed no relationship. For example, in reports from the Nurses Health Study and Health Professionals' Follow-up Study, there was no significant relation between tea consumption, although interestingly there was a relationship with coffee consumption $[59,60]$. There also was no relation between tea consumption and diabetes in a large cohort of 46,906 African American Women [61]. Despite these negative studies, Huxley and colleagues completed a meta-analysis examining the effects of caffeinated beverages on incident diabetes combining data from 18 studies with information from nearly half a million individuals [62]. In regard to tea, they found that overall the relative risk of new diabetes was significantly reduced (RR $0.84,95 \%$ CI $0.73-0.94$ ). 
As for the other risk factors discussed above, clinical intervention studies examining the effects of tea and tea polyphenols on endpoints related to diabetes provide additional insight into the question of whether tea might affect diabetes mellitus. Hosoda and colleagues observed that consumption of oolong tea $(1,500 \mathrm{ml} /$ day $)$ for 30 days in a placebo controlled crossover study lowered fasting glucose in 20 patients with type 2 diabetes mellitus on hypoglycemic drugs [63]. Consumption of one gram of black tea by healthy volunteers lowered the blood glucose and blood insulin responses to an oral glucose load (glucose tolerance test) suggesting an improvement in insulin sensitivity [64].

In contrast, Fukino and colleagues completed a placebo controlled study examining the effects of green tea (administered as a extract powder containing $544 \mathrm{mg}$ polyphenols mixed with hot water) in a group of 66 patients with diabetes mellitus or borderline diabetes [65]. Compared to the effects of placebo, there were no effects of green tea on measures of glycemic status, including blood glucose, insulin, hemoglobin A1C, or the homeostasis model assessment of insulin resistance (HOMA-IR). Interpretation of this study is complicated by a relatively similar intake of polyphenols in the active $(747 \mathrm{mg} / \mathrm{d})$ and placebo $(469 \mathrm{mg} / \mathrm{d})$ groups and the observation that these glycemic variables improved in both the active and placebo groups. It is possible that an effect of green tea would have been detected if polyphenol intake had been limited in the placebo group, as is often done in studies of this type. Ryu and colleagues also observed no effect of green tea consumption compared to water in a crossover for four weeks in 55 patients with type 2 diabetes mellitus.

Interestingly, there have been studies showing an effect of tea consumption on body weight. For example, Chantre and colleagues administered green tea extract to moderately obese subjects for 3 months observed a $4.6 \%$ decrease in body weight and $4.5 \%$ decrease in waist circumference by $4.48 \%$ [66]. In a study of 38 healthy Japanese men with normal body mass index randomized to consume green tea or a low catechin control, Nagao and colleagues reported that green tea consumption produced a $2.4 \mathrm{~kg}$ decrease in body weight and favorable effects on waist circumference, body fat mass, skin-fold thickness, and total subcutaneous fat areas (tested by computed tomography) [67]. The same group subsequently completed a larger randomized, placebo-controlled study in 240 Japanese men and women and observed a $1.7 \mathrm{~kg}$ decrease in body weight and significant changes in body fat and fat distribution with consumption of green tea extract [36]. Recently, Basu and colleagues showed a decrease in body weight following eight weeks of green tea or green tea extract compared to placebo in a group of 35 obese individuals with the metabolic syndrome [49]. The mechanisms accounting for weight loss with tea or tea components remain unclear. It has been suggested that they may increase sympathetic nervous system activity and stimulate thermogenesis, which would increase calorie consumption [68].

As for other risk factors, the available studies provide inconsistent findings. Some studies showed weight loss and reduction of diabetes, while others did not. Differences in study population and tea preparation likely explain these inconsistencies. Overall, the available evidence, including a large meta-analysis, suggests that tea consumption reduces the incidence of new diabetes mellitus. There is a modest level of evidence supporting a favorable effect of tea components on insulin sensitivity. Finally, tea consumption appears to induce a modest amount of weight loss. These conclusions must be tempered by the possibility of publication bias and the relatively small size of most of the published intervention studies.

\section{Mechanistic studies with tea and cardiovascular diseases}

Experimental and translational clinical studies have provided further insight into the mechanisms of benefit for tea against cardiovascular disease and Table 1 contains a partial 
list of such mechanisms. These include antioxidant effects, anti-inflammatory effects, and improvement of endothelial function. This section will review these possible mechanisms.

\subsection{Antioxidant effects of tea and tea components}

According to the oxidative hypothesis of atherosclerosis, LDL oxidation is a key step in the atherogenic process [69]. Based this hypothesis, considerable effort was made to determine whether antioxidant compounds that inhibit LDL oxidation might prevent cardiovascular disease in humans [70]. A large number of studies, including large clinical trials were conducted, and overall there remains little evidence that antioxidant supplements, including vitamins $\mathrm{E}$ and $\mathrm{C}$ and beta carotene, reduce cardiovascular disease. While it is clear that atherosclerosis is associated with increased oxidative stress, it is now understood that reactive oxygen species play important signaling roles in the vasculature and that simply scavenging reactive oxygen species or inhibiting LDL oxidation is not an effective strategy to inhibit atherosclerosis [71]. In this context, it is known that tea polyphenols have antioxidant effects in vitro [72-75] and many studies sought evidence for antioxidant effects of tea in humans.

In regard to in vitro effects, tea and tea extracts have been shown to scavenge superoxide and other reactive oxygen species [76]. Tea and tea components have also been shown inhibit lipid peroxidation [75,77-80]. Furthermore, exposure of isolated endothelial cells to tea limits their ability to oxidize LDL [81]. Tea flavonoids can chelate redox active metal ions, which limits production of reactive oxygen species via the Fenton reaction [82]. There is animal evidence for antioxidant effects of tea following oral administration [83-85]. Consistent with the more recent human data, green and black tea inhibited LDL oxidation following oral administration to hypercholesterolemic rabbits, but the effect did not relate to changes in extent of atherosclerosis [84].

As mentioned, studies show that tea influences plasma antioxidant status in humans. For example, several studies have shown that tea consumption increases the ability of plasma to scavenge reactive oxygen species $[46,86,87]$. Studies have also shown that LDL isolated from plasma is less susceptible to oxidation following tea consumption [88], while other studies have failed to show such an effect $[51,75,87,89,90]$. In regard to preventing oxidation of lipids, proteins, or DNA in vivo, the evidence for beneficial effects of tea are less clear. Hakim and colleagues reported that green tea, but not black tea, by cigarette smokers decreased urinary levels of 8-hydroxy-deoxyguanosine, a marker of DNA oxidation [91]. Klaunig and colleagues reported a similar finding [92]. Erba and colleagues reported a reduction of DNA oxidative damage in lymphocytes isolated from healthy volunteers [46]. Other studies failed to show evidence that consumption of tea inhibits markers of lipid or DNA oxidation in human subjects [90,93,94].

As was observed in intervention studies examining the effects of tea consumption on risk factors, the data are mixed regarding antioxidant effects of tea consumption. Some of the discrepant results may reflect differences in tea preparations and the studied populations. Overall, there are reasonably convincing studies to indicate that consumption of tea or tea components can influence antioxidant capacity plasma. However, the bulk of the evidence does not support an in vivo antioxidant effect following consumption of relevant amounts of tea.

\subsection{Anti-inflammatory effects}

Inflammation is now known to be an integral part of atherosclerosis and is involved from the earliest stages of atherogenesis to later stages of plaque vulnerability and rupture, which causes clinical events such as myocardial infarction and stroke [95]. There is strong 
evidence in experimental models and in animals that suggest anti-inflammatory effects of tea and tea components. In vitro studies have shown favorable effects on inflammatory cells. For example, EGCG inhibits migration of neutrophils through an endothelial cell monolayer [96], decreases the activity of neutrophil elastase [97], and reduces ROS production and chemokine-induced chemotaxis of neutrophils $[98,99]$. EGCG also inhibits adhesion and migration of CD8+ T cells [100]. EGCG and other catechins have been shown to inhibit cytokine-induced adhesion molecule expression and monocyte adhesion in cultured endothelial cells [101]. EGCG blocked lipopolysaccharide-induced tumor necrosis factor alpha (TNF-alpha) production and lethality in mice [102] and had reduced inflammatory activation in the lung in a mouse model of pulmonary fibrosis [103].

In humans, epidemiological and intervention studies have examined anti-inflammatory effects of tea consumption. Serum levels of C-reactive protein and other markers of inflammation relate strongly to cardiovascular risk, and several epidemiological studies examined the effects of tea consumption on such markers. For example, tea consumption was inversely related to C-reactive protein levels in a cohort of 1031 health men [104]. Other studies failed to show such a relationship $[58,105,106]$. More generally, flavonoid consumption and fruit and vegetable consumption are associated with lower levels of Creactive protein $[107,108]$, making it harder to confirm a specific relationship with tea consumption.

In regard to intervention studies, Neyestani and colleagues reported a decrease in C-reactive protein following consumption of black tea extract for four weeks in 46 patients with type 2 diabetes mellitus [109]. Steptoe and colleagues also reported a decrease in C-reactive protein and pro-inflammatory monocyte-platelet aggregates following four weeks of black tea consumption in healthy men [110]. Green tea consumption reduced C-reactive protein levels in male smokers [111]. Other well-done studies, however, showed no such effects in patients with risk factors or coronary artery disease $[65,90,112,113]$.

As has been observed for other tea intervention studies, the discrepant results are likely attributable to differences in tea preparations and patient characteristics. No formal metaanalysis has examined the effects of tea consumption on C-reactive protein or other markers of inflammation. However, the bulk of the evidence does not suggest a strong antiinflammatory effect of tea consumption, despite promising experimental studies.

\subsection{Endothelial function}

The endothelium is a major regulator of vascular homeostasis and controls arterial tone, thrombosis, the composition of the arterial wall, and local inflammation by production of a variety of factors, including nitric oxide nitric oxide [114]. Abnormalities of endothelial function relate to cardiovascular risk factors, predict cardiovascular events, and respond to risk reduction therapies, including drugs, lifestyle changes, and dietary interventions. Recently, there have been several studies showing beneficial effects of tea on endothelial function, particularly endothelium-dependent vasodilation.

In a placebo-controlled crossover study, Duffy and colleagues showed that consumption of black tea (900 $\mathrm{ml}$ per day for four weeks) improved endothelium-dependent flow-mediated dilation of the brachial artery in patients with coronary artery disease [115]. Hodgson and colleagues showed a similar benefit of black tea consumption in patients with mildly elevated cholesterol levels [116]. Green tea has also been reported to improve brachial artery flow-mediated dilation $[117,118]$ and circulating endothelial progenitor cells, which contribute to maintenance of vascular health [118]. One study suggested that green and black tea have equivalent effects on flow-mediated dilation in post-menopausal women [119]. Favorable effects on endothelial function have been reported with tea components, 
including EGCG [120]. In addition to improving FMD, green tea improves endotheliumdependent dilation of forearm microvessels in response to acetylcholine infusion in cigarette smokers and this improvement was associated with an increase in plasma nitric oxide [111]. On the other hand, tea consumption had no effect on carotid-femoral pulse wave velocity, a measure of arterial stiffness that depends in part on endothelial function [121].

Experimental studies have shed light on the mechanisms accounting for improved nitric oxide bioavailability following tea consumption. Initially investigators hypothesized that tea flavonoids might scavenge reactive oxygen species and prevent "inactivation" of nitric oxide, but as discussed above, there is little evidence that the plasma concentrations of tea flavonoids achieved following tea consumption are high enough to act via this mechanism. More recent studies indicate that tea extracts and individual tea polyphenols, including EGCG stimulate phosphorylation of endothelial nitric oxide synthase (eNOS) at serine 1177, a response that increases production of nitric oxide. The response occur via activation of the phosphatidylinositol 3-kinase (PI3 kinase)/Akt signaling pathway [122-124]. Subsequent studies suggest that this process also involves activation of p38 MAP kinase and transactivation of estrogen receptor alpha [125].

A number of other mechanisms contribute to the observed increase in eNOS activity following exposure of endothelial cells to tea components. For example, green tea polyphenols down regulate expression of caveolin-1 (Cav-1), an negative regulator of eNOS activity and this effect also involves activation of p38 MAP kinase [126]. Other polyphenol mixtures have been shown to activate AMP-kinase, a key regulator of cellular energy status, which also leads to activation of PI3K/Akt and eNOS phosphorylation [127].

Overall, there is a large body of working showing that tea consumption improves endothelium-dependent vasodilation in healthy human subjects and in patients with risk factors and established atherosclerosis. The effects are particularly strong following acute consumption of tea and occur despite acute effects of caffeinated tea to increase blood pressure. Many studies also show sustained improvements in endothelial function with longer-term tea consumption, while purified EGCG has an acute, but no chronic effect [120]. Experimental studies provide strong evidence that tea acts via specific signaling pathways in endothelial cells that are relevant to the pathogenesis of atherosclerosis. Given the strong links between endothelial dysfunction and the pathogenesis of atherosclerosis, a favorable effect of tea on the endothelium is a plausible mechanism that might account for reduced cardiovascular risk among individuals with higher tea consumption.

\subsection{Anti-platelet effects}

It is well established that clinical coronary syndromes such as unstable angina and acute myocardial infarction involve platelet aggregation and that anti-platelet agents such as aspirin and clopidogrel reduce cardiovascular risk [95]. A number of experimental studies suggest that tea has anti-platelet effects that might reduce cardiovascular risk. For example, Kang and colleagues reported that administration of EGCG or green tea extract to mice prolongs bleeding time, and prevents collagen-induced pulmonary thrombosis and death [128]. They also observed that EGCG inhibits agonist-induced aggregation of human platelets in vitro. The effects may be attributed to alterations in intracellular calcium signaling [129] and prostaglandin metabolism [130]. Theaflavins in black tea and green tea catechins have been shown to be potent inhibitors of platelet activating factor biosynthesis and platelet aggregation in a rabbit model [131]. It is important to note that the concentrations of EGCG and other tea components used in some of these in vitro studies (50 to $100 \mu \mathrm{M}$ ), greatly exceed the concentrations measurable in plasma following consumption of tea or EGCG supplement in humans [90,120]. 
In regard to human studies, Hodgson and colleagues observed that tea consumption by healthy volunteers reduced plasma levels of P-selectin, a marker of in vivo platelet aggregation, but ex vivo platelet aggregation was unaffected in that study [132]. Green tea consumption also lowered P-selectin levels in male smokers [112]. Steptoe and colleagues observed that black tea consumption for four weeks reduced platelet-leukocyte aggregates, an important measure of platelet activation that is relevant to coronary plaque rupture [110]. Duffy and colleagues also observed no effect of tea consumption on ex vivo platelet aggregation following consumption of black tea in patients with coronary artery disease [133], although that study may be limited by the background aspirin treatment in all of the study subjects.

In general, studies that examined ex vivo platelet aggregation failed to show beneficial effects, but measures of in vivo platelet activation appear to be improved following tea consumption. Experimental studies provide evidence of plausible mechanisms. Thus, the bulk of the available data support the hypothesis that platelet inhibitory effects might explain the observed relations between tea consumption and reduced cardiovascular risk.

\subsection{Anti-proliferative effects}

Another mechanism that might affect cardiovascular disease is the observed antiproliferative and anti-migratory effects of tea components on vascular smooth muscle cells. EGCG arrests vascular smooth muscle cell proliferation in the G1 phase of the cell cycle and decreases the proliferative response following arterial injury in apolipoprotein E-null mice, a dyslipidemic model that is prone to develop atherosclerosis [134]. EGCG also inhibits vascular smooth muscle cell activation and proliferation by platelet-derived growth factor [135]. EGCG inhibits vascular smooth muscle cell migration through a reconstituted basement membrane barrier in an in vitro model that is relevant to atherogenesis [136]. Although there currently is no human evidence of such an effect, the anti-proliferative properties of EGCG have prompted investigators to consider developing EGCG-eluting polymeric stents for prevent of restenosis following angioplasty, a process that is primarily driven by vascular smooth muscle cell proliferation and migration [137].

\section{Clinical Implications}

The reviewed epidemiological studies and meta-analyses suggest that tea has protective effects against cardiovascular disease. In regard to the mechanisms that might account for such effects, there is evidence that tea might lower blood pressure and have favorable effects on blood lipids, glucose, and body weight. In addition, experimental studies and human intervention studies suggest that tea may have anti-inflammatory, anti-thrombotic, and antiproliferative effects, and may improve the function of the vascular endothelium. Although tea polyphenols can scavenge reactive oxygen species and protect LDL against oxidation in vitro, human studies argue against an important in vivo anti-oxidant effect of tea. While the effects are modest compared to the effects of pharmacological interventions, in the opinion of the authors, the overall evidence suggests that tea consumption reduces cardiovascular risk by plausible mechanisms. The case for tea is strengthened by a similar body of work for protective effects of other polyphenol-containing foods and beverages such as grapes and red wine, cocoa, berries, and other fruits and vegetables [21,53,138-140]. The question is whether these findings translate to specific dietary recommendations for the general population and for patients with cardiovascular disease.

Making specific dietary recommendations about tea consumption as an approach to prevent or treat cardiovascular disease is problematic for several reasons. Importantly, there are no randomized clinical outcome trials with tea. Epidemiological studies of tea are unavoidably confounded by the lifestyles of tea drinkers and non-tea drinkers, background tea intake of 
the population, and many other factors. Most of the current management guidelines in the field of cardiovascular disease, particularly recommendations about drug treatment, are based on randomized clinical trials and meta-analyses of clinical trials that can control for such factors. There have been randomized studies of dietary approaches such as the Mediterranean diet to reduce cardiovascular risk, but none with tea. In drug studies, the control group can be randomized to a placebo and have zero intake of the studied factor. Tea, on the other hand, is a ubiquitous part of the diet and it is not possible or ethical to have a control group that consumes no tea over the three to five years needed to accumulate a sufficient number of cardiovascular events.

A number of other difficulties would make it extraordinarily difficult to conduct a randomized clinical trial with tea. It remains unclear what type and dose of tea to recommend or to study. Another barrier is the question of specific populations studied. Pharmaceutical studies focus on patients with cardiovascular disease, but the results are not expected to apply to the general population. Finally, there is the question of cost. Clinical outcome studies are extraordinarily expensive and unlike pharmaceutical studies, there is no sponsor with a profit motive to bear the cost of studying a whole food, such as tea.

Similar issues influence the utility of the available observational studies to guide dietary recommendations. The available epidemiological studies suggest favorable effects of green, oolong, and black tea and benefit from modest to only extremely high amounts of tea consumption. Smaller scale intervention studies looking at risk factors and mechanistic surrogate endpoints also examined a wide variety and types and doses of tea. Variable bioavailability due to differences in food matrix and human gut absorption further clouds the issue. Thus, it is remains extremely difficult to formulate dietary recommendations about how much and the type of tea to consume for the general population. Making recommendations for disease population is even more problematic.

Another important clinical implication of the reviewed studies is the potential use of tea extracts or individual tea components, such as EGCG, to promote cardiovascular health or prevent cardiovascular disease. Food, beverage and dietary supplement products designed to promote heart health are now a multi-billion dollar category in the U.S., with comparable markets in Europe, Japan and Australia. In regard to extracts, there is a lack of uniformity to the studied preparations, doses, and endpoints that make it hard to make specific recommendations and as for whole tea, there are no randomized outcome studies. For purified components, such as EGCG, there is a large body of evidence for favorable effects, but studies suggest that the benefits are limited to short-term acute effects reflective of the short plasma half-life of one to two hours [120]. To be beneficial, some type of slow-release preparation would be needed to provide a sustained increase in blood levels. Consideration of such preparations likely crosses the line from dietary supplements to drugs, with the attendant regulatory issues.

In 2006, Ito En, Ltd., a manufacturer of green tea and green tea products filed a petition to the U.S. Food and Drug Administration (FDA) to make a qualified health claim for green tea and green tea extracts based on studies showing favorable effects on cardiovascular disease risk factors [141]. The FDA reviewed observational studies that examined the relationship between green tea and cardiovascular disease endpoints, including many of the studies discussed in this review. They also considered intervention studies that examined the effects of green tea on blood pressure and blood cholesterol as surrogate endpoints for cardiovascular disease. Although they considered many observational studies, they argued that intervention studies provide the most scientifically valid information. For this reason, they particularly focused on four intervention studies that failed to show a benefit of green tea on blood pressure [34] and lipids [51,87,142] and three intervention studies that failed to 
show an effect of green tea extract on cholesterol $[51,93,143]$. On the basis of these studies, they concluded that there was no credible evidence to support a relationship between consumption of green tea and reduced risk of cardiovascular disease. They cited the data for vitamin $\mathrm{E}$ and folate as examples of other dietary supplements that showed strong associations in observational studies, but no benefit in randomized trials, further justifying their decision to discount many of the observational studies suggesting favorable effects. While they did not find that green tea was unhealthy, the decided that the available evidence did not support a qualified health claim for a benefit against cardiovascular disease. Table 2 continues a partial list of randomized intervention studies examining effects of tea on risk factors that have been published since the FDA ruling in 2006. Many of these studies show benefit, raising the possibility that the question of a qualified health claim for tea might be reconsidered.

At this time, however, manufacturers cannot make claims about benefits against cardiovascular disease in advertising and labels for green tea or black tea. Advertising claims are different from guidelines and recommendations from non-commercial entities, such as the American Heart Association (AHA). In the most recent dietary guidelines, the Nutrition Committee of the AHA recommended that individuals consume a diet rich in fruits and vegetables to reduce the risk for cardiovascular disease [144]. Such a diet includes green and black tea.

\section{Conclusion}

In this article, we have reviewed a representative portion of the extensive published literature on tea and its role in cardiovascular disease prevention. Some, but not all observational studies suggest a reduction in cardiovascular disease. There also are mixed data about the effects of tea on risk factors from observational and intervention studies. Mechanistic studies in experimental models and human subjects have identified a number of plausible mechanisms of benefit, including anti-inflammatory and anti-platelet effects as well as favorable effects on the vascular endothelium. No randomized trials have examined the effects of tea on cardiovascular events, and there are many barriers to the conduct of such a trial. Thus, no definite conclusion can be drawn from the current data and no specific dietary recommendations can be made about whether tea promotes reduces risk for cardiovascular disease. Furthermore, the available literature does not provide a clear answer about the type and/or amount of tea that should be consumed as part of a heart healthy diet.

At the present time, it is clear that tea is a popular, economical and safe drink which is enjoyed daily by millions of people all across the world. Given the high consumption and distribution of tea worldwide and the potential health effects of tea, further study is justified. In the meantime, freshly brewed green or black tea appears to be a reasonable dietary choice to consider as part of lifestyle and dietary approach to prevent heart disease.

\section{Acknowledgments}

Dr. Vita previously received research grant support from the North America Tea Trade Health Research Association, Unilever, Inc., Welch's, Inc., USANA Health Sciences, Inc. He has current research grants from DSM Nutritional Products, Ocean Spray, Inc., The Almond Board of California. He has received consultation fee or speaker honoraria from Unilever, USANA, DSM, Ocean Spray, and the Almond Board of California. He also is supported by research grants from the National Institutes of Health (HL083801, HL081587, HL083269, and HL75795 and HL102299). 


\section{References}

1. Kris-Etherton PM, Hecker KD, Bonanome A, Coval SM, Binkoski AE, Hilpert KF, et al. Bioactive compounds in foods: their role in the prevention of cardiovascular disease and cancer. Am J Med. 2002; 113(Suppl 9B):71S-88S. [PubMed: 12566142]

2. Balentine DA, Wiseman SA, Bouwens LC. The chemistry of tea flavonoids. Crit Rev Food Sci Nutr. 1997; 37:693-704. [PubMed: 9447270]

3. Sato Y, Nakatsuka H, Watanabe T, Hisamichi S, Shimizu H, Fujisaku S, et al. Possible contribution of green tea drinking habits to the prevention of stroke. Tohoku J Exp Med. 1989; 157:337-43. [PubMed: 2741170]

4. Nakachi K, Matsuyama S, Miyake S, Suganuma M, Imai K. Preventive effects of drinking green tea on cancer and cardiovascular disease: epidemiological evidence for multiple targeting prevention. Biofactors. 2000; 13:49-54. [PubMed: 11237198]

5. Kuriyama S, Shimazu T, Ohmori K, Kikuchi N, Nakaya N, Nishino Y, et al. Green tea consumption and mortality due to cardiovascular disease, cancer, and all causes in Japan: the Ohsaki study. JAMA. 2006; 296:1255-65. [PubMed: 16968850]

6. Liang W, Lee AH, Binns CW, Huang R, Hu D, Zhou Q. Tea consumption and ischemic stroke risk: a case-control study in southern China. Stroke. 2009; 40:2480-5. [PubMed: 19478218]

7. Mineharu Y, Koizumi A, Wada Y, Iso H, Watanabe Y, Date C, et al. Coffee, green tea, black tea and oolong tea consumption and risk of mortality from cardiovascular disease in Japanese men and women. J Epidemiol Community Health. 2010

8. Sesso HD, Gaziano JM, Buring JE, Hennekens CH. Coffee and tea intake and the risk of myocardial infarction. Am J Epidemiol. 1999; 149:162-7. [PubMed: 9921961]

9. Mukamal KJ, Maclure M, Muller JE, Sherwood JB, Mittleman MA. Tea consumption and mortality after acute myocardial infarction. Circulation. 2002; 105:2476-81. [PubMed: 12034652]

10. Mukamal KJ, Alert M, Maclure M, Muller JE, Mittleman MA. Tea consumption and infarctrelated ventricular arrhythmias: the determinants of myocardial infarction onset study. J Am Coll Nutr. 2006; 25:472-9. [PubMed: 17229893]

11. de Koning Gans JM, Uiterwaal CS, van der Schouw YT, Boer JM, Grobbee DE, Verschuren WM, et al. Tea and coffee consumption and cardiovascular morbidity and mortality. Arterioscler Thromb Vasc Biol. 2010; 30:1665-71. [PubMed: 20562351]

12. Stensvold I, Tverdal A, Solvoll K, Foss OP. Tea consumption. relationship to cholesterol, blood pressure, and coronary and total mortality. Prev Med. 1992; 21:546-53. [PubMed: 1409496]

13. Brown CA, Bolton-Smith C, Woodward M, Tunstall-Pedoe H. Coffee and tea consumption and the prevalence of coronary heart disease in men and women: results from the Scottish Heart Health Study. J Epidemiol Community Health. 1993; 47:171-5. [PubMed: 8350026]

14. Hertog MG, Sweetnam PM, Fehily AM, Elwood PC, Kromhout D. Antioxidant flavonols and ischemic heart disease in a Welsh population of men: the Caerphilly Study. Am J Clin Nutr. 1997; 65:1489-94. [PubMed: 9129481]

15. Vita JA. Tea consumption and cardiovascular disease: effects on endothelial function. J Nutr. 2003; 133:3293S-7S. [PubMed: 14519828]

16. Sesso HD, Gaziano JM, Liu S, Buring JE. Flavonoid intake and the risk of cardiovascular disease in women. Am J Clin Nutr. 2003; 77:1400-8. [PubMed: 12791616]

17. Sesso HD, Paffenbarger RS Jr, Oguma Y, Lee IM. Lack of association between tea and cardiovascular disease in college alumni. Int J Epidemiol. 2003; 32:527-33. [PubMed: 12913023]

18. Rimm EB, Katan MB, Ascherio A, Stampfer MJ, Willett WC. Relation between intake of flavonoids and risk for coronary heart disease in male health professionals. Ann Intern Med. 1996; 125:384-9. [PubMed: 8702089]

19. Peters U, Poole C, Arab L. Does tea affect cardiovascular disease? a meta-analysis. Am J Epidemiol. 2001; 154:495-503. [PubMed: 11549554]

20. Arab L, Liu W, Elashoff D. Green and black tea consumption and risk of stroke: a meta-analysis. Stroke. 2009; 40:1786-92. [PubMed: 19228856] 
21. Hertog MGL, Feskens EJM, Hollman PCH, Martijn B, Kromhout D. Dietary antioxidant flavonoids and risk of coronary heart disease: The Zutphen Elderly Study. Lancet. 1993; 342:1007-11. [PubMed: 8105262]

22. Hertog MGL, Feskens EJM, Kromhout D. Antioxidant flavanols and coronary heart disease risk. Lancet. 1997; 349:699. [PubMed: 9078206]

23. Keli SO, Hertog MGL, Feskens EJM, Kromhout D. Dietary flavanoids, antioxidant vitamins, and incidence of stroke: the Zutphen study. Arch Intern Med. 1996; 156 (6):637-42. [PubMed: 8629875]

24. Hertog MGL, Kromhout D, Aravanis C, Blackburn H, Buzino R, Fidanza F. Flavonoid intake and long-term risk of coronary heart disease and cancer in the Seven Countries Study. Arch Intern Med. 1995; 155 (4):381-6. [PubMed: 7848021]

25. Hirvonen T, Pietinen P, Virtanen M, Ovaskainen ML, Hakkinen S, Albanes D, et al. Intake of flavonols and flavones and risk of coronary heart disease in male smokers. Epidemiology. 2001; 12:62-7. [PubMed: 11138821]

26. Huxley RR, Neil HA. The relation between dietary flavonol intake and coronary heart disease mortality: a meta-analysis of prospective cohort studies. Eur J Clin Nutr. 2003; 57:904-8. [PubMed: 12879084]

27. Hollman PC, Geelen A, Kromhout D. Dietary flavonol intake may lower stroke risk in men and women. J Nutr. 2010; 140:600-4. [PubMed: 20089788]

28. Hodgson JM, Devine A, Puddey IB, Chan SY, Beilin LJ, Prince RL. Tea intake is inversely related to blood pressure in older women. J Nutr. 2003; 133:2883-6. [PubMed: 12949382]

29. Chobanian AV, Bakris GL, Black HR, Cushman WC, Green LA, Izzo JL Jr, et al. Seventh report of the Joint National Committee on Prevention, Detection, Evaluation, and Treatment of High Blood Pressure. Hypertension. 2003; 42:1206-52. [PubMed: 14656957]

30. Yang YC, Lu FH, Wu JS, Wu CH, Chang CJ. The protective effect of habitual tea consumption on hypertension. Arch Intern Med. 2004; 164:1534-40. [PubMed: 15277285]

31. Klatsky AL, Friedman GD, Armstrong MA. The relationships between alcoholic beverage use and other traits to blood pressure: a new Kaiser Permanente study. Circulation. 1986; 73:628-36. [PubMed: 3948365]

32. Klatsky AL, Armstrong MA, Friedman GD. Coffee, tea, and mortality. Ann Epidemiol. 1993; 3:375-81. [PubMed: 8275213]

33. Wakabayashi K, Kono S, Shinchi K, Honjo S, Todoroki I, Sakurai Y, et al. Habitual coffee consumption and blood pressure: A study of self-defense officials in Japan. Eur J Epidemiol. 1998; 14:669-73. [PubMed: 9849827]

34. Hodgson JM, Puddey IB, Burke V, Beilin LJ, Jordan N. Effects on blood pressure of drinking green and black tea. J Hypertens. 1999; 17:457-63. [PubMed: 10404946]

35. Hodgson JM, Burke V, Puddey IB. Acute effects of tea on fasting and postprandial vascular function and blood pressure in humans. J Hypertens. 2005; 23:47-54. [PubMed: 15643124]

36. Nagao T, Hase T, Tokimitsu I. A green tea extract high in catechins reduces body fat and cardiovascular risks in humans. Obesity (Silver Spring). 2007; 15:1473-83. [PubMed: 17557985]

37. Brown AL, Lane J, Coverly J, Stocks J, Jackson S, Stephen A, et al. Effects of dietary supplementation with the green tea polyphenol epigallocatechin-3-gallate on insulin resistance and associated metabolic risk factors: randomized controlled trial. Br J Nutr. 2009; 101:886-94. [PubMed: 18710606]

38. Nantz MP, Rowe CA, Bukowski JF, Percival SS. Standardized capsule of Camellia sinensis lowers cardiovascular risk factors in a randomized, double-blind, placebo-controlled study. Nutrition. 2009; 25:147-54. [PubMed: 18848434]

39. Taubert D, Roesen R, Schomig E. Effect of cocoa and tea intake on blood pressure: a metaanalysis. Arch Intern Med. 2007; 167:626-34. [PubMed: 17420419]

40. Kono S, Shinchi K, Ikeda N, Yanai F, Imanishi K. Green tea consumption and serum lipid profiles: a cross-sectional study in northern Kyushu, Japan. Prev Med. 1992; 21:526-31. [PubMed: 1409494] 
41. Hakim IA, Alsaif MA, Alduwaihy M, Al Rubeaan K, Al Nuaim AR, Al Attas OS. Tea consumption and the prevalence of coronary heart disease in Saudi adults: results from a Saudi national study. Prev Med. 2003; 36:64-70. [PubMed: 12473426]

42. Tsubono Y, Tsugane S. Green tea intake in relation to serum lipid levels in Middle-aged Japanese men and women. Ann Epidemiol. 1997; 7:280-4. [PubMed: 9177111]

43. Davies MJ, Judd JT, Baer DJ, Clevidence BA, Paul DR, Edwards AJ, et al. Black tea consumption reduces total and LDL cholesterol in mildly hypercholesterolemic adults. J Nutr. 2003; 133:3298S-302S. [PubMed: 14519829]

44. Maron DJ, Lu GP, Cai NS, Wu ZG, Li YH, Chen H, et al. Cholesterol-lowering effect of a theaflavin-enriched green tea extract: a randomized controlled trial. Arch Intern Med. 2003; 163:1448-53. [PubMed: 12824094]

45. Unno T, Tago M, Suzuki Y, Nozawa A, Sagesaka YM, Kakuda T, et al. Effect of tea catechins on postprandial plasma lipid responses in human subjects. Br J Nutr. 2005; 93:543-7. [PubMed: 15946418]

46. Erba D, Riso P, Bordoni A, Foti P, Biagi PL, Testolin G. Effectiveness of moderate green tea consumption on antioxidative status and plasma lipid profile in humans. J Nutr Biochem. 2005; 16:144-9. [PubMed: 15741048]

47. Fujita H, Yamagami T. Antihypercholesterolemic effect of Chinese black tea extract in human subjects with borderline hypercholesterolemia. Nutr Res. 2008; 28:450-6. [PubMed: 19083445]

48. Bertipaglia, dS; Mandarino, MG.; Cardoso, JR.; Dichi, I.; Dichi, JB.; Camargo, AE., et al. Association between soy and green tea (Camellia sinensis) diminishes hypercholesterolemia and increases total plasma antioxidant potential in dyslipidemic subjects. Nutrition. 2008; 24:562-8. [PubMed: 18455656]

49. Basu A, Sanchez K, Leyva MJ, Wu M, Betts NM, Aston CE, et al. Green tea supplementation affects body weight, lipids, and lipid peroxidation in obese subjects with metabolic syndrome. $\mathrm{J}$ Am Coll Nutr. 2010; 29:31-40. [PubMed: 20595643]

50. Trautwein EA, Du Y, Meynen E, Yan X, Wen Y, Wang H, et al. Purified black tea theaflavins and theaflavins/catechin supplements did not affect serum lipids in healthy individuals with mildly to moderately elevated cholesterol concentrations. Eur J Nutr. 2010; 49:27-35. [PubMed: 19639377]

51. Princen HM, van Duyvenvoorde W, Buytenhek R, Blonk C, Tijburg LB, Langius JA, et al. No effect of consumption of green and black tea on plasma lipid and antioxidant levels and on LDL oxidation in smokers. Arterioscler Thromb Vasc Biol. 1998; 18:833-41. [PubMed: 9598844]

52. Fenercioglu AK, Saler T, Genc E, Sabuncu H, Altuntas Y. The effects of polyphenol-containing antioxidants on oxidative stress and lipid peroxidation in Type 2 diabetes mellitus without complications. J Endocrinol Invest. 2010; 33:118-24. [PubMed: 19834314]

53. Hooper L, Kroon PA, Rimm EB, Cohn JS, Harvey I, Le Cornu KA, et al. Flavonoids, flavonoidrich foods, and cardiovascular risk: a meta-analysis of randomized controlled trials. Am J Clin Nutr. 2008; 88:38-50. [PubMed: 18614722]

54. Mokdad AH, Bowman BA, Ford ES, Vinicor F, Marks JS, Koplan JP. The continuing epidemics of obesity and diabetes in the United States. JAMA. 2001; 286:1195-200. [PubMed: 11559264]

55. Iso H, Date C, Wakai K, Fukui M, Tamakoshi A. The relationship between green tea and total caffeine intake and risk for self-reported type 2 diabetes among Japanese adults. Ann Intern Med. 2006; 144:554-62. [PubMed: 16618952]

56. Greenberg JA, Axen KV, Schnoll R, Boozer CN. Coffee, tea and diabetes: the role of weight loss and caffeine. Int J Obes (Lond). 2005; 29:1121-9. [PubMed: 15925959]

57. Hamer M, Witte DR, Mosdol A, Marmot MG, Brunner EJ. Prospective study of coffee and tea consumption in relation to risk of type 2 diabetes mellitus among men and women: the Whitehall II study. Br J Nutr. 2008; 100:1046-53. [PubMed: 18315891]

58. Song Y, Manson JE, Buring JE, Sesso HD, Liu S. Associations of dietary flavonoids with risk of type 2 diabetes, and markers of insulin resistance and systemic inflammation in women: a prospective study and cross-sectional analysis. J Am Coll Nutr. 2005; 24:376-84. [PubMed: 16192263] 
59. Salazar-Martinez E, Willett WC, Ascherio A, Manson JE, Leitzmann MF, Stampfer MJ, et al. Coffee consumption and risk for type 2 diabetes mellitus. Ann Intern Med. 2004; 140:1-8. [PubMed: 14706966]

60. van Dam RM, Willett WC, Manson JE, Hu FB. Coffee, caffeine, and risk of type 2 diabetes: a prospective cohort study in younger and middle-aged U.S. women. Diabetes Care. 2006; 29:398403. [PubMed: 16443894]

61. Boggs DA, Rosenberg L, Ruiz-Narvaez EA, Palmer JR. Coffee, tea, and alcohol intake in relation to risk of type 2 diabetes in African American women. Am J Clin Nutr. 2010; 92:960-6. [PubMed: 20826625]

62. Huxley R, Lee CM, Barzi F, Timmermeister L, Czernichow S, Perkovic V, et al. Coffee, decaffeinated coffee, and tea consumption in relation to incident type 2 diabetes mellitus: a systematic review with meta-analysis. Arch Intern Med. 2009; 169:2053-63. [PubMed: 20008687]

63. Hosoda K, Wang MF, Liao ML, Chuang CK, Iha M, Clevidence B, et al. Antihyperglycemic effect of oolong tea in type 2 diabetes. Diabetes Care. 2003; 26:1714-8. [PubMed: 12766099]

64. Bryans JA, Judd PA, Ellis PR. The effect of consuming instant black tea on postprandial plasma glucose and insulin concentrations in healthy humans. J Am Coll Nutr. 2007; 26:471-7. [PubMed: 17914136]

65. Fukino Y, Shimbo M, Aoki N, Okubo T, Iso H. Randomized controlled trial for an effect of green tea consumption on insulin resistance and inflammation markers. J Nutr Sci Vitaminol (Tokyo). 2005; 51:335-42. [PubMed: 16392704]

66. Chantre P, Lairon D. Recent findings of green tea extract AR25 (Exolise) and its activity for the treatment of obesity. Phytomedicine. 2002; 9:3-8. [PubMed: 11924761]

67. Nagao T, Komine Y, Soga S, Meguro S, Hase T, Tanaka Y, et al. Ingestion of a tea rich in catechins leads to a reduction in body fat and malondialdehyde-modified LDL in men. Am J Clin Nutr. 2005; 81:122-9. [PubMed: 15640470]

68. Dulloo AG, Seydoux J, Girardier L, Chantre P, Vandermander J. Green tea and thermogenesis: interactions between catechin-polyphenols, caffeine and sympathetic activity. Int J Obes Relat Metab Disord. 2000; 24:252-8. [PubMed: 10702779]

69. Witztum JL, Steinberg D. Role of oxidized low density lipoprotein in atherogenesis. J Clin Invest. 1991; 88:1785-92. [PubMed: 1752940]

70. Stocker R, Keaney JF Jr. The role of oxidative modifications in atherosclerosis. Physiol Rev. 2004; 84:1381-478. [PubMed: 15383655]

71. Münzel T, Keaney JF Jr. Are ACE-inhibitors a "magic bullet" against oxidative stress? Circulation. 2001; 104:1571-4. [PubMed: 11571254]

72. Morel I, Lescoat G, Cogrel P, Sergent O, Pasdeloup N, Brissot P, et al. Antioxidant and ironchelating activities of the flavonoids catechin, quercetin and diosmetin on iron-loaded rat hepatocyte cultures. Biochem Pharmacol. 1993; 45:13-9. [PubMed: 8424806]

73. Katiyar SK, Agarwal R, Mukhtar H. Inhibition of spontaneous and photo-enhanced lipid peroxidation in mouse epidermal microsomes by epicatechin derivatives from green tea. Cancer Lett. 1994; 79:61-6. [PubMed: 8187054]

74. Terao J, Piskula M, Yao Q. Protective effect of epicatechin, epicatechin gallate, and quercetin on lipid peroxidation in phospholipid bilayers. Arch Biochem Biophys. 1994; 308:278-84. [PubMed: 8311465]

75. Cherubini A, Beal MF, Frei B. Black tea increases the resistance of human plasma to lipid peroxidation in vitro, but not ex vivo. Free Radic Biol Med. 1999; 27:381-7. [PubMed: 10468212]

76. Nakagawa T, Yokozawa T. Direct scavenging of nitric oxide and superoxide by green tea. Food Chem Toxicol. 2002; 40:1745-50. [PubMed: 12419687]

77. Miura S, Watanabe J, Tomita T, Sano M, Tomita I. The inhibitory effects of tea polyphenols (flavan 3-ol derivatives) on $\mathrm{Cu} 2$ mediated oxidative modification of low density lipoprotein. Biol Pharm Bull. 1994; 17(12):1567-72. [PubMed: 7735196]

78. Osada K, Takahashi M, Hoshina S, Nakamura M, Nakamura S, Sugano M. Tea catechins inhibit cholesterol oxidation accompanying oxidation of low density lipoprotein in vitro. Comp Biochem Physiol C Toxicol Pharmacol. 2001; 128:153-64. [PubMed: 11239828] 
79. Ishikawa T, Suzukawa M, Ito T, Yoshida H, Ayaori M. Effect of tea flavonoid supplementation on the susceptibility of low-density lipoprotein to oxidative modification. Am J Clin Nutr. 1997; 66:261-6. [PubMed: 9250103]

80. Yang TT, Koo MW. Inhibitory effect of Chinese green tea on endothelial cell-induced LDL oxidation. Atherosclerosis. 2000; 148:67-73. [PubMed: 10580172]

81. Yoshida H, Ishikawa T, Hosoai H, Suzukawa M, Ayaori M, Hisada T, et al. Inhibitory effect of tea flavonoids on the ability of cells to oxidize low density lipoprotein. Biochem Pharmacol. 1999; 58:1695-703. [PubMed: 10571243]

82. Frei B, Higdon JV. Antioxidant activity of tea polyphenols in vivo: evidence from animal studies. J Nutr. 2003; 133:3275S-84S. [PubMed: 14519826]

83. Vinson JA, Dabbagh YA. Effect of green and black tea supplementation on lipids, lipid oxidation and fibrinogen in the hamster: mechanisms for the epidemiological benefits of tea drinking. FEBS Lett. 1998; 433:44-6. [PubMed: 9738930]

84. Tijburg LB, Wiseman SA, Meijer GW, Weststrate JA. Effects of green tea, black tea and dietary lipophilic antioxidants on LDL oxidizability and atherosclerosis in hypercholesterolaemic rabbits. Atherosclerosis. 1997; 135:37-47. [PubMed: 9395271]

85. Miura Y, Chiba T, Tomita I, Koizumi H, Miura S, Umegaki K, et al. Tea catechins prevent the development of atherosclerosis in apoprotein E-deficient mice. J Nutr. 2001; 131:27-32. [PubMed: 11208934]

86. Serafini M, Ghiselli A, Ferro-Luzzi A. In vivo antioxidant effect of green and black tea in man. Eur J Clin Nut. 1996; 50 (1):28-32.

87. van het H, de Boer HS, Wiseman SA, Lien N, Westrate JA, Tiburg LBM. Consumption of green or black tea does not increase the resistance of LDL to oxidation in humans. Am J Clin Nutr. 1997; 66:1125-32. [PubMed: 9356529]

88. Gomikawa S, Ishikawa Y, Hayase W, Haratake Y, Hirano N, Matuura H, et al. Effect of ground green tea drinking for 2 weeks on the susceptibility of plasma and LDL to the oxidation ex vivo in healthy volunteers. Kobe J Med Sci. 2008; 54:E62-E72. [PubMed: 18772610]

89. het Hof KH, Wiseman SA, Yang CS, Tijburg LB. Plasma and lipoprotein levels of tea catechins following repeated tea consumption. Proc Soc Exp Biol Med. 1999; 220:203-9. [PubMed: 10202389]

90. Widlansky ME, Duffy SJ, Hamburg NM, Gokce N, Warden BA, Wiseman S, et al. Effects of black tea consumption on plasma catechins and markers of oxidative stress and inflammation in patients with coronary artery disease. Free Radic Biol Med. 2005; 38:499-506. [PubMed: 15649652]

91. Hakim IA, Harris RB, Brown S, Chow HH, Wiseman S, Agarwal S, et al. Effect of increased tea consumption on oxidative DNA damage among smokers: a randomized controlled study. J Nutr. 2003; 133:3303S-9S. [PubMed: 14519830]

92. Klaunig JE, Xu Y, Han C, Kamendulis LM, Chen J, Heiser C, et al. The effect of tea consumption on oxidative stress in smokers and nonsmokers. Proc Soc Exp Biol Med. 1999; 220:249-54. [PubMed: 10202398]

93. Freese R, Basu S, Hietanen E, Nair J, Nakachi K, Bartsch H, et al. Green tea extract decreases plasma malondialdehyde concentration but does not affect other indicators of oxidative stress, nitric oxide production, or hemostatic factors during a high-linoleic acid diet in healthy females. Eur J Nutr. 1999; 38:149-57. [PubMed: 10443337]

94. O'Reilly JD, Mallet AI, McAnlis GT, Young IS, Halliwell B, Sanders TA, et al. Consumption of flavonoids in onions and black tea: lack of effect on $\mathrm{F}(2)$-isoprostanes and autoantibodies to oxidized LDL in healthy humans. Am J Clin Nutr. 2001; 73:1040-4. [PubMed: 11382657]

95. Libby P. Atherosclerosis: the new view. Sci Am. 2002; 286:46-55. [PubMed: 11951331]

96. Hofbauer R, Frass M, Gmeiner B, Handler S, Speiser W, Kapiotis S. The green tea extract epigallocatechin gallate is able to reduce neutrophil transmigration through monolayers of endothelial cells. Wien Klin Wochenschr. 1999; 111:278-82. [PubMed: 10355038]

97. Sartor L, Pezzato E, Garbisa S. (-)Epigallocatechin-3-gallate inhibits leukocyte elastase: potential of the phyto-factor in hindering inflammation, emphysema, and invasion. J Leukoc Biol. 2002; 71:73-9. [PubMed: 11781382] 
98. Dona M, Dell'Aica I, Calabrese F, Benelli R, Morini M, Albini A, et al. Neutrophil restraint by green tea: inhibition of inflammation, associated angiogenesis, and pulmonary fibrosis. J Immunol. 2003; 170:4335-41. [PubMed: 12682270]

99. Takano K, Nakaima K, Nitta M, Shibata F, Nakagawa H. Inhibitory effect of (-)-epigallocatechin 3 -gallate, a polyphenol of green tea, on neutrophil chemotaxis in vitro and in vivo. J Agric Food Chem. 2004; 52:4571-6. [PubMed: 15237969]

100. Kawai K, Tsuno NH, Kitayama J, Okaji Y, Yazawa K, Asakage M, et al. Epigallocatechin gallate attenuates adhesion and migration of CD8+ T cells by binding to CD11b. J Allergy Clin Immunol. 2004; 113:1211-7. [PubMed: 15208607]

101. Ludwig A, Lorenz M, Grimbo N, Steinle F, Meiners S, Bartsch C, et al. The tea flavonoid epigallocatechin-3-gallate reduces cytokine-induced VCAM-1 expression and monocyte adhesion to endothelial cells. Biochem Biophys Res Commun. 2004; 316:659-65. [PubMed: 15033450]

102. Yang F, de Villiers WJ, McClain CJ, Varilek GW. Green tea polyphenols block endotoxininduced tumor necrosis factor-production and lethality in a murine model. J Nutr. 1998; 128:2334-40. [PubMed: 9868178]

103. Sueoka N, Suganuma M, Sueoka E, Okabe S, Matsuyama S, Imai K, et al. A new function of green tea: prevention of lifestyle-related diseases. Ann N Y Acad Sci. 2001; 928:274-80. [PubMed: 11795518]

104. De Bacquer D, Clays E, Delanghe J, De Backer G. Epidemiological evidence for an association between habitual tea consumption and markers of chronic inflammation. Atherosclerosis. 2006; 189:428-35. [PubMed: 16442546]

105. Maki T, Pham NM, Yoshida D, Yin G, Ohnaka K, Takayanagi R, et al. The relationship of coffee and green tea consumption with high-sensitivity C-reactive protein in Japanese men and women. Clin Chem Lab Med. 2010; 48:849-54. [PubMed: 20441477]

106. Villegas R, Xiang YB, Cai H, Elasy T, Cai Q, Zhang X, et al. Lifestyle determinants of C-reactive protein in middle-aged, urban Chinese men. Nutr Metab Cardiovasc Dis. 2010

107. Chun OK, Chung SJ, Claycombe KJ, Song WO. Serum C-reactive protein concentrations are inversely associated with dietary flavonoid intake in U.S. adults. J Nutr. 2008; 138:753-60. [PubMed: 18356331]

108. Esmaillzadeh A, Kimiagar M, Mehrabi Y, Azadbakht L, Hu FB, Willett WC. Fruit and vegetable intakes, C-reactive protein, and the metabolic syndrome. Am J Clin Nutr. 2006; 84:1489-97. [PubMed: 17158434]

109. Neyestani TR, Shariatzade N, Kalayi A, Gharavi A, Khalaji N, Dadkhah M, et al. Regular daily intake of black tea improves oxidative stress biomarkers and decreases serum C-reactive protein levels in type 2 diabetic patients. Ann Nutr Metab. 2010; 57:40-9. [PubMed: 20668372]

110. Steptoe A, Gibson EL, Vuononvirta R, Hamer M, Wardle J, Rycroft JA, et al. The effects of chronic tea intake on platelet activation and inflammation: a double-blind placebo controlled trial. Atherosclerosis. 2007; 193:277-82. [PubMed: 17010979]

111. Oyama J, Maeda T, Kouzuma K, Ochiai R, Tokimitsu I, Higuchi Y, et al. Green tea catechins improve human forearm endothelial dysfunction and have antiatherosclerotic effects in smokers. Circ J. 2010; 74:578-88. [PubMed: 20134098]

112. Lee W, Min WK, Chun S, Lee YW, Park H, Lee DH, et al. Long-term effects of green tea ingestion on atherosclerotic biological markers in smokers. Clin Biochem. 2005; 38:84-7. [PubMed: 15607322]

113. Basu A, Du M, Sanchez K, Leyva MJ, Betts NM, Blevins S, et al. Green tea minimally affects biomarkers of inflammation in obese subjects with metabolic syndrome. Nutrition. 2010

114. Tabit CE, Chung WB, Hamburg NM, Vita JA. Endothelial dysfunction in diabetes mellitus: molecular mechanisms and clinical implications. Rev Endocr Metab Disord. 2010; 11:61-74. [PubMed: 20186491]

115. Duffy SJ, Keaney JF Jr, Holbrook M, Gokce N, Swerdloff PL, Frei B, et al. Short- and long-term black tea consumption reverses endothelial dysfunction in patients with coronary artery disease. Circulation. 2001; 104:151-6. [PubMed: 11447078] 
116. Hodgson JM, Puddey IB, Burke V, Watts GF, Beilin LJ. Regular ingestion of black tea improves brachial artery vasodilator function. Clin Sci (Lond). 2002; 102:195-201. [PubMed: 11834139]

117. Alexopoulos N, Vlachopoulos C, Aznaouridis K, Baou K, Vasiliadou C, Pietri P, et al. The acute effect of green tea consumption on endothelial function in healthy individuals. Eur J Cardiovasc Prev Rehabil. 2008; 15:300-5. [PubMed: 18525384]

118. Kim W, Jeong MH, Cho SH, Yun JH, Chae HJ, Ahn YK, et al. Effect of green tea consumption on endothelial function and circulating endothelial progenitor cells in chronic smokers. Circ J. 2006; 70:1052-7. [PubMed: 16864941]

119. Jochmann N, Lorenz M, Krosigk A, Martus P, Bohm V, Baumann G, et al. The efficacy of black tea in ameliorating endothelial function is equivalent to that of green tea. Br J Nutr. 2008; 99:863-8. [PubMed: 17916273]

120. Widlansky ME, Hamburg NM, Anter E, Holbrook M, Kahn DF, Elliott JG, et al. Acute EGCG supplementation reverses endothelial dysfunction in patients with coronary artery disease. J Am Coll Nutr. 2007; 26:95-102. [PubMed: 17536120]

121. Ryu OH, Lee J, Lee KW, Kim HY, Seo JA, Kim SG, et al. Effects of green tea consumption on inflammation, insulin resistance and pulse wave velocity in type 2 diabetes patients. Diabetes Res Clin Pract. 2006; 71:356-8. [PubMed: 16169629]

122. Lorenz M, Wessler S, Follmann E, Michaelis W, Dusterhoft T, Baumann G, et al. A constituent of green tea, epigallocatechin-3-gallate, activates endothelial nitric oxide synthase by a phosphatidylinositol-3-OH-kinase-, cAMP-dependent protein kinase-, and Akt-dependent pathway and leads to endothelial-dependent vasorelaxation. J Biol Chem. 2004; 279:6190-5. [PubMed: 14645258]

123. Anter E, Thomas SR, Schulz E, Shapira OM, Vita JA, Keaney JF Jr. Activation of eNOS by the p38 MAP kinase in response to black tea polyphenols. J Biol Chem. 2004; 45:46637-43. [PubMed: 15333638]

124. Kim JA, Formoso G, Li Y, Potenza MA, Marasciulo FL, Montagnani M, et al. Epigallocatechin gallate, a green tea polyphenol, mediates NO-dependent vasodilation using signaling pathways in vascular endothelium requiring reactive oxygen species and Fyn. J Biol Chem. 2007; 282:1373645. [PubMed: 17363366]

125. Anter E, Chen K, Shapira OM, Karas RH, Keaney JF Jr. p38 mitogen-activated protein kinase activates eNOS in endothelial cells by an estrogen receptor alpha-dependent pathway in response to black tea polyphenols. Circ Res. 2005; 96:1072-8. [PubMed: 15879307]

126. Li Y, Ying C, Zuo X, Yi H, Yi W, Meng Y, et al. Green tea polyphenols down-regulate caveolin-1 expression via ERK1/2 and p38MAPK in endothelial cells. J Nutr Biochem. 2009; 20:1021-7. [PubMed: 19195865]

127. Zang M, Xu S, Maitland-Toolan KA, Zuccollo A, Hou X, Jiang B, et al. Polyphenols stimulate AMP-activated protein kinase, lower lipids, and inhibit accelerated atherosclerosis in diabetic LDL receptor-deficient mice. Diabetes. 2006; 55:2180-91. [PubMed: 16873680]

128. Kang WS, Lim IH, Yuk DY, Chung KH, Park JB, Yoo HS, et al. Antithrombotic activities of green tea catechins and (-)-epigallocatechin gallate. Thromb Res. 1999; 96:229-37. [PubMed: 10588466]

129. Kang WS, Chung KH, Chung JH, Lee JY, Park JB, Zhang YH, et al. Antiplatelet activity of green tea catechins is mediated by inhibition of cytoplasmic calcium increase. J Cardiovasc Pharmacol. 2001; 38:875-84. [PubMed: 11707691]

130. Jin YR, Im JH, Park ES, Cho MR, Han XH, Lee JJ, et al. Antiplatelet activity of epigallocatechin gallate is mediated by the inhibition of PLCgamma2 phosphorylation, elevation of PGD2 production, and maintaining calcium-ATPase activity. J Cardiovasc Pharmacol. 2008; 51:45-54. [PubMed: 18209568]

131. Sugatani J, Fukazawa N, Ujihara K, Yoshinari K, Abe I, Noguchi H, et al. Tea polyphenols inhibit acetyl-CoA:1-alkyl-sn-glycero-3-phosphocholine acetyltransferase (a key enzyme in platelet-activating factor biosynthesis) and platelet-activating factor-induced platelet aggregation. Int Arch Allergy Immunol. 2004; 134:17-28. [PubMed: 15051936] 
132. Hodgson JM, Puddey IB, Mori TA, Burke V, Baker RI, Beilin LJ. Effects of regular ingestion of black tea on haemostasis and cell adhesion molecules in humans. Eur J Clin Nutr. 2001; 55:8816. [PubMed: 11593350]

133. Duffy SJ, Vita JA, Holbrook M, Swerdloff PL, Keaney JF Jr. Effect of acute and chronic tea consumption on platelet aggregation in patients with coronary artery disease. Arterioscler Thromb Vasc Biol. 2001; 21:1084-9. [PubMed: 11397724]

134. Chyu KY, Babbidge SM, Zhao X, Dandillaya R, Rietveld AG, Yano J, et al. Differential effects of green tea-derived catechin on developing versus established atherosclerosis in apolipoprotein E-null mice. Circulation. 2004

135. Ahn HY, Hadizadeh KR, Seul C, Yun YP, Vetter H, Sachinidis A. Epigallocathechin-3 gallate selectively inhibits the PDGF-BB-induced intracellular signaling transduction pathway in vascular smooth muscle cells and inhibits transformation of sis-transfected NIH 3T3 fibroblasts and human glioblastoma cells (A172). Mol Biol Cell. 1999; 10:1093-104. [PubMed: 10198059]

136. Maeda K, Kuzuya M, Cheng XW, Asai T, Kanda S, Tamaya-Mori N, et al. Green tea catechins inhibit the cultured smooth muscle cell invasion through the basement barrier. Atherosclerosis. 2003; 166:23-30. [PubMed: 12482547]

137. Han DW, Lee JJ, Jung DY, Park JC, Hyon SH. Development of epigallocatechin gallate-eluting polymeric stent and its physicochemical, biomechanical and biological evaluations. Biomed Mater. 2009; 4:044104. [PubMed: 19584425]

138. Dohadwala MM, Vita JA. Grapes and cardiovascular disease. J Nutr. 2009

139. Maron DJ. Flavonoids for reduction of atherosclerotic risk. Curr Atheroscler Rep. 2004; 6:73-8. [PubMed: 14662111]

140. Buijsse B, Feskens EJ, Kok FJ, Kromhout D. Cocoa intake, blood pressure, and cardiovascular mortality: the Zutphen Elderly Study. Arch Intern Med. 2006; 166:411-7. [PubMed: 16505260]

141. Food and Drug Administration [Internet]. Qualified health claims: Letter of denial - Green tea and reduced risk of cardiovascular disease (Docket No. 2005Q-0297). 2006. [Cited 2010 Dec 23]. Available from: http://www.fda.gov/Food/LabelingNutrition/LabelClaims/QualifiedHealthClaims/ ucm073207.htm

142. Hirano-Ohmori R, Takahashi R, Momiyama Y, Taniguchi H, Yonemura A, Tamai S, et al. Green tea consumption and serum malondialdehyde-modified LDL concentrations in healthy subjects. J Am Coll Nutr. 2005; 24:342-6. [PubMed: 16192258]

143. Young JF, Dragstedt LO, Haraldsdottir J, Daneshvar B, Kall MA, Loft S, et al. Green tea extract only affects markers of oxidative status postprandially: lasting antioxidant effect of flavonoidfree diet. Br J Nutr. 2002; 87:343-55. [PubMed: 12064344]

144. Lichtenstein AH, Appel LJ, Brands M, Carnethon M, Daniels S, Franch HA, et al. Diet and lifestyle recommendations revision 2006: a scientific statement from the American Heart Association Nutrition Committee. Circulation. 2006; 114:82-96. [PubMed: 16785338] 
Table 1

Potential Mechanisms of Benefit for Tea Against Cardiovascular Disease

\begin{tabular}{l}
\hline Blood pressure lowering \\
Improved dyslipidemia \\
Improved insulin sensitivity \\
Weight loss \\
Antioxidant effects - scavenging reactive oxygen species and preventing oxidation of lipids, proteins, and DNA \\
Anti-inflammatory effects \\
Improved endothelial function \\
Platelet inhibition \\
Inhibition of smooth muscle cell proliferation and migration
\end{tabular}

Pharmacol Res. Author manuscript; available in PMC 2012 August 1. 


\section{Table 2}

Intervention studies of tea on blood pressure and lipids since the FDA decision in 2006

\begin{tabular}{|c|c|c|c|}
\hline First author [reference] & Endpoint & Study design & Result \\
\hline Nagao [36] & Body fat, LDL, blood pressure & $\begin{array}{l}\text { Green tea extract, randomized parallel } \\
\text { group, } 12 \text { weeks, } n=240\end{array}$ & Benefit \\
\hline Bertigaglia de Santana [48] & LDL, HDL, triglycerides & $\begin{array}{l}\text { Green tea, randomized parallel group, } 90 \\
\text { days, } n=25 \text { per group }\end{array}$ & No benefit \\
\hline Fujita [47] & LDL, triglycerides, body weight & $\begin{array}{l}\text { Black tea, randomized parallel group, } 3 \\
\text { months, } n=47\end{array}$ & Benefit \\
\hline Brown [37] & Blood pressure, LDL, HDL, & $\begin{array}{l}\text { EGCG, randomized parallel group, } 8 \\
\text { weeks, } n=88\end{array}$ & $\begin{array}{l}\text { Benefit on blood pressure, } \\
\text { no benefit for lipids }\end{array}$ \\
\hline Nantz [38] & Blood pressure, LDL & $\begin{array}{l}\text { Tea extract, randomized parallel group, } 3 \\
\text { weeks, } n=111\end{array}$ & $\begin{array}{l}\text { Benefit on LDL and blood } \\
\text { pressure }\end{array}$ \\
\hline Basu [49] & Blood pressure, LDL, body weight & $\begin{array}{l}\text { Green tea extract, randomized parallel } \\
\text { group, } 8 \text { weeks, } n=35\end{array}$ & $\begin{array}{l}\text { Benefit on body weight, no } \\
\text { benefit on LDL }\end{array}$ \\
\hline Trautwein [50] & Serum lipids & $\begin{array}{l}\text { Black tea extract, randomized parallel } \\
\text { group, } 11 \text { weeks, } n=102\end{array}$ & No benefit \\
\hline Hooper [53] & LDL & $\begin{array}{l}\text { Meta-analysis of } 133 \text { green tea intervention } \\
\text { studies }\end{array}$ & Benefit on LDL \\
\hline
\end{tabular}

$\mathrm{LDL}=$ low density lipoprotein cholesterol, $\mathrm{HDL}=$ high density lipoprotein cholesterol 